\title{
Dissociation of conditioned emotional and avoidance responses due to ECS'
}

LAUREN K. GERBRANDT

CLAREMONT GRADUATE SCHOOL

\begin{abstract}
Eight daily passive avoidance trials were given to two groups of rats punished either with footshock or electroconvulsive shock. The rats were compared in the learning of conditioned emotional responses and avoidance learning. The results indicated a greater conditioning of emotionality under ECS than footshock. ECS, however, seemed to produce a dissociation between emotionality and avoidance since rats avoided ECS only slightly in comparison to footshock. The results are discussed in terms of their theoretical relevance.
\end{abstract}

\section{Introduetion}

The associations between a conditioned emotional response (CER), such as fear, and avoidance responding are well substantiated. The formation of a CER has been shown to be effective in providing the motivation for learning new avoidance responses (Miller, 1948; May, 1948). Miller noted that rats defecated and urinated more after shock and apparatus cues were paired. Maher \& McIntyre (1960) have substantiated this finding. By measuring the suppressant effect of a CER on an operant behavior while the rats are learning to avoid a shock, Kamin, Brimer \& Black (1963) have shown that both the CER and the avoidance response increase monotonically during early learning. When the shock was unavoidable the rats continued to show strong CER effects with continued trials.

Dissociations between the CER and avoidance responding are also found under some conditions. Kamin, Brimer \& Black (1963) found that in later learning trials the probability of a correct avoidance was increasing while the CER effect was diminishing. On the other hand, the CER effect was found to be quite strong when the rats were extinguishing on the avoidance response. Maher \& McIntyre (1960) have reported no differences in CER between frontal cortex lesioned and control rats, even though strong deficits in avoidance responding have been found as a result of frontal lesions (Thompson, 1964).

There is also some reason to believe electroconvulsive shock (ECS) can produce a dissociation between avoidance responding and the CER. Although Coons \& Miller (1960) report a greatly increased CER as a result of ECS treatments, Gerbrandt \& Thomson (1964) and Hudspeth et al (1964) have found very little evidence for an avoidance of ECS as compared to footshock. The present study will directly compare the formation of a CER with the acquisition of an avoidance response when either footshock or ECS are used as punishment.

\section{Method}

Thirty-two naive descendents of the Tryon Maze Dull $\left(\mathrm{S}^{3}\right)$ strain of rats were given one of two types of punishment in the passive avoidance situation and apparatus described previously (Gerbrandt \& Thomson, 1964). One half of the animals received a footshock of $80 \mathrm{~V}$ ac when they stepped from the small "safe" platform onto the floor. The remaining animals received a $0.2 \mathrm{sec}$. ECS consisting of an ac current of 35 ma when they stepped from the platform onto the floor of the apparatus. An avoidance was measured as a $30 \mathrm{sec}$. duration of staying on the platform. All rats were given eight daily trials of avoidance training. All rats wore the ECS ear-clips during the learning trials.

Each rat was observed for urination or defecation while being carried from its home cage and being introduced into the avoidance apparatus with ear-clips attached. Any amounts of urination or defecation were each rated as one point for each rat.

\section{Results and Diseussion}

In substantiation of results obtained in a previous study (Gerbrandt \& Thomson, 1964), footshock was far superior to ECS in producing avoidance responding during trials $1-4\left(\mathrm{X}^{2}=44.5 ; \mathrm{df}=1 ; \mathrm{p}<.001\right)$ and trials $5-8\left(X^{2}=58.9 ; d f=1 ; p<.001\right)$. In support of the notion that ECS produces a dissociation between the CER and avoidance responding, however, ECS was even more effective than was footshock in producing emotionality during trials $1-4\left(\mathrm{X}^{2}=12: 9 ; \mathrm{df}=2 ; \mathrm{p}<.01\right)$, trials $5-8$ $\left(X^{2}=13.6 ; d f=2 ; p<.01\right)$, and in the treatment and trials interaction $\left(X^{2}=13.6 ; d f=2 ; p<.01\right)$. These results are clearly indicated in Fig. 1. The emotionality measure and avoidance learning for the footshock condition are closely associated. On the other hand, emotionality increases greatly with continued ECS treatments although avoidance learning is slight.

These results are crucial in determining the validity of the recent hypothesis of ECS effects advanced by Lewis \& Maher (1965). The authors note that fractional components of the ECS-induced convulsion may become conditioned to situational cues. These cues could then elicit these components in competition with the response to be learned. The authors note further than any "amnesia" in an avoidance learning situation may then be explained as a reduction in the necessary CER for avoidance as a result of the conditioned inhibition-or competing and conditioned relaxational components of the convulsion. The experi- 


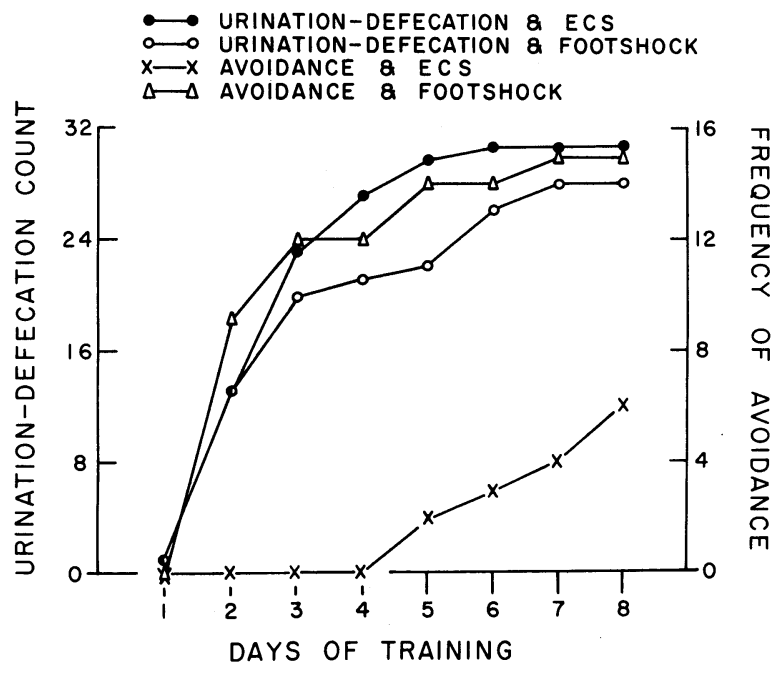

Fig. 1. ECS induced dissociation of emotional and avoidance responding.

menter, handling, and ECS ear-clips used in the present study are all cues which should have resulted in reductions in emotionality according to Lewis \& Maher (1965). Quite the opposite results were obtained in this study. Coons \& Miller (1960) also report significantly greater emotionality in groups given immediate ECS as compared to groups given an ECS $1 \mathrm{hr}$. after daily trials. It would then seem that conclusions for the existence of amnesic effects of ECS are justified (Madsen \& McGaugh, 1961; Hudspeth, McGaugh, \& Thomson, 1964; Gerbrandt \& Thomson, 1964). No justification for the competing response theory (Lewis \& Maher, 1965) has been found either in these investigations or in the present study.

\section{References}

Coons, E. E., \& Miller, N. E. Conflict versus consolidation of memory traces to explain "retrograde amnesia" produced by ECS. J. comp. physiol. Psychol., 1960, 53, 524-531.

Gerbrandt, L. K., \& Thomson, C. W. Competing response and amnesic effects of electroconvulsive shock under extinction and incentive shifts. J. comp. physiol. Psychol., 1964, 58, 208-211.

Hudspeth, W. J., McGaugh, J. L., \& Thomson, C. W. The aversive and amnesic effects of electroconvulsive shock. J.comp. physiol, Psychol., 1964, 57, 61-64.

Kamin, L. J., Brimer, C. J., \& Black, A. H. Conditioned suppression as a monitor of fear of the CS in the course of avoidance training. J. comp. physiol. Psychol., 1963, 56, 497-501.

Lewis, D. J., \& Maher, B. A. Neural consolidation and electroconvulsive shock. Psychol. Bull., 1965,

Madsen, M. C., \& McGaugh, J. L. The effect of ECS on one-trial avoidance learning. J. comp. physiol. Psychol., 1961, 54, 522-523.

Maher, B. A., \& McIntyre, R. W. The extinction of the CER following frontal ablation. J. comp. physiol. Psychol., 1960, 53, 549-552.

May, M. A. Experimentally acquired drives. J. exp. Psychol., 1948 38, 66-77.

Miller, N. E. Studies of fear as an acquirable drive: I. Fear as motivation and feareduction as reinforcement in the learning of new responses. J. exp. Psychol., 1948, 38, 89-101.

\section{Note}

1. This paper was supported in part by Research Grant MY-3541 to J. L. McGaugh from the National Institute of Mental Health and was prepared during the author's tenure under Research Fellowship MH-21492 from the National Institute of Mental Health. 